\title{
Synthesis, Structure, and Catalytic Activity of Au/Poly(ethylene terephthalate) Composites
}

\begin{abstract}
A. Mashentseva ${ }^{a, b, *}$, D. Borgekov ${ }^{a}$, M. Zdorovets $^{a, b}$ And A. Russakova $^{a}$
${ }^{a}$ The L.N. Gumilyov Eurasian National University, Munaitpasov Str., 5, 010008, Astana, Kazakhstan

${ }^{b}$ Astana Branch of the Institute of Nuclear Physics, Abylai-khan Av., 2/1, 010008, Astana, Kazakhstan

A standard technique of electroless gold deposition was modified by changing the composition of Ag-based activation solution. This allows preparation of two types of poly(ethyleneterephthalate) (PET) track etched membranes coated entirely with gold after 1,5 , and $24 \mathrm{~h}$ of reaction at $4{ }^{\circ} \mathrm{C}$. After dissolving the polymer template, gold nanotubes with outer diameter of 70-80 $\mathrm{nm}$ were characterized by scanning electron microscopy, energy dispersive X-ray spectroscopy, and X-ray diffraction. Reduction of p-nitrophenol to p-aminophenol by sodium borohydride was used to investigate the catalytic activity of as-prepared Au/PET membrane. All experiments were carried out for five consecutive cycles and rate constant of the pseudo-first-order reaction was calculated. It was found that $\mathrm{Au} / \mathrm{Ag} / \mathrm{PET}$ composites prepared after activation for $3 \mathrm{~min}$ in Ag-based solution (with potassium sodium tartrate as reducing agent) more effective catalyst $\left(k=0.087 \mathrm{~min}^{-1}\right)$ was obtained when the Au/PET samples activated with ammonia silver nitrate solution $\left(k=0.041 \mathrm{~min}^{-1}\right)$.
\end{abstract}

DOI: 10.12693 /APhysPolA.125.1263

PACS: 62.23.Pq, 82.65. $+\mathrm{r}$, 82.20.Pm

\section{Introduction}

Heavy ions irradiated nanoporous track etched membranes (TeMs) have significant applications not only in separation processes as fine filters but also in nanotechnology as flexible template for synthesis of highly ordered nanowires or nanotube arrays [1-3]. One of the most prospective materials to be used is a gold due to its unique properties in nanosized scale. Gold nanotube based (GNT) membranes are widely used in selective molecular separation $[4,5]$, biosensing $[6,7]$ and electroanalysis $[8,9]$. Another promising direction of GNT membrane application is membrane catalysis [11] because the polymer membrane is very flexible, has a high surface area and can be easily handled as composite or could be dissolved to prepare free-standing GNTs.

The aim of this work is improving the gold deposition technique by modification of Ag-based activation solution (AS), characterisation of its structure and composition as well as examination of prepared $\mathrm{Au} / \mathrm{PET}$ composites as catalyst.

\section{Experimental part}

PET film with a nominal thickness of $12 \mu \mathrm{m}$ was irradiated with $1.75 \mathrm{MeV} /$ nucl $\mathrm{Kr}$-ion beam with the ion fluency of $1 \times 10^{9} \mathrm{~cm}^{-2}$ at the DC-60 cyclotron in the Institute of Nuclear Physics in Astana and etched in $2.2 \mathrm{M}$ sodium hydroxide solution at $85^{\circ} \mathrm{C}$ for $70 \mathrm{~s}$ that yielded $80 \mathrm{~nm}$ wide cylindrical pores. The effective pore sizes of parent template as well as inner diameter of GNTs were estimated by gas permeability measurement using the equation

*corresponding author; e-mail: mashentseva.a@gmail.com

$$
Q=\frac{4 \pi r^{3}}{3 l} \sqrt{\frac{2 \pi}{R T M}} \Delta p
$$

where $Q-$ molar flow rate of air through the pore, $R-$ the gas constant, $M$ - molecular weight, $L-$ membrane thickness, $\Delta p$ - applied pressure.

The standard electroless technique described by Sexton et al. [7] was used for deposition of gold from sulphite plating solution, prepared from chloroauric acid according to procedure described in [12].

At the first stage the track-etched PET membrane was immersed into a solution of $\mathrm{SnCl}_{2}(25 \mathrm{~g} / \mathrm{L})$ and hydrochloric acid $(60 \mathrm{~g} / \mathrm{L})$ for $15 \mathrm{~min}$ to sensitize polymer surface and thoroughly rinsed for 15 min under flowing water. At the next stage, called activation, the sensitized membrane was immersed to Ag-based solution to provide formation of the thin layer of silver nanoparticles that acts as a catalyst for further reduction of $\mathrm{Au}(\mathrm{I})$ to $\mathrm{Au}(0)$. First activation solution $\mathrm{AS}_{\mathrm{I}}$ consists of two parts: part A is $101.3 \mathrm{~g} / \mathrm{L} \mathrm{AgNO}_{3}, 83.7 \mathrm{~g} / \mathrm{L} 25 \% \mathrm{NH}_{3}$ and part $\mathrm{B}$ is $31.3 \mathrm{~g} / \mathrm{L} \mathrm{MgSO}_{4} \cdot 7 \mathrm{H}_{2} \mathrm{O}$ and $436.8 \mathrm{~g} / \mathrm{L}$ $\mathrm{KNaC}_{4} \mathrm{O}_{6} \mathrm{H}_{4}$. Part A and part $\mathrm{B}$ were mixed with water in ratio 1:1:5 respectively. Another $\mathrm{AS}_{\text {II }}$ "classical" ammonia solution was prepared by "drop-by-drop" titration of $1.0 \mathrm{ml}$ of $10 \% \mathrm{AgNO}_{3}$ with concentrated ammonia solution until the precipitate completely dissolved after addition of $3.3 \mathrm{ml} 3 \% \mathrm{NaOH}$, and titration was repeated again until the precipitate just dissolved. Solution was filtered and PET membrane was activated for $5 \mathrm{~min}$.

After activation in Ag-plating solutions all samples was thoroughly rinsed with deionized water and dried with $\mathrm{N}_{2}$. Electroless $\mathrm{Au}$ deposition was performed in plating solution (as prepared Au-sulphite solution and solution of $0.127 \mathrm{M} \mathrm{Na}_{2} \mathrm{SO}_{3}$ and $0.625 \mathrm{M}$ of formaldehyde was mixed in proportion 1:10) for duration of desired deposition times $(1.0,5.0$, and $24 \mathrm{~h})$ at $\mathrm{pH}=12.0$ and 
temperature $0-4{ }^{\circ} \mathrm{C}$. Finally the Au-plated membrane was washed in water and ethanol and dried with air.

Scanning electron microscopy (SEM) and energy-dispersive X-ray spectroscopy (EDAX) were performed using a JEOL-7500F (JEOL, Japan) equipped with iXRF EDS-2000 (Oxford Instruments). Prior to the measurement, the PET template was removed by dissolving in dichloromethane.

X-ray diffraction (XRD) pattern was obtained on a D8 Advance (Bruker, Germany) to study the crystalline structure of the sample with a fixed anode $\mathrm{Cu}$ source. $\mathrm{X}$-ray was generated at $40 \mathrm{~mA}$ and $40 \mathrm{kV}$, and the scanning position ranged from $20-90^{\circ} 2(\theta)$. The crystal gold grain size was calculated from the diffractogram peak shape using the Scherrer equation

$$
\tau=\frac{k \lambda}{\beta \cos \theta},
$$

where the shape factor $k=0.9, \lambda$ is $1.54 \AA, \beta$ - the full width half maximum (FWHM) and $\theta-$ the Bragg angle.

The catalytic activity of $\mathrm{Au} / \mathrm{PET}$ membranes was determined by reduction of 4-nitrophenol (4-NP) to 4-aminophenol (4-AP) by $\mathrm{NaBH}_{4}$ according to the following experimental procedure [11]: the reaction mixture of $50 \mathrm{ml}$ of $4-\mathrm{NP}$ and sodium borohydride aqueous solution was first put into a $150 \mathrm{ml}$ beaker with a magnetic stirrer and a cover glass, keeping the final concentration of 4-NP at $3.91 \times 10^{-6} \mathrm{M}$ and $\mathrm{NaBH}_{4}$ at $3.91 \times 10^{-3} \mathrm{M}$. The large excess concentration of sodium borohydride was used to make the reaction independent of this parameter. Afterwards the sample of $\mathrm{Au} / \mathrm{PET}$ membrane (weighing about $30 \mathrm{mg}$ ) was immersed in the same beaker and catalytic activity was monitored every 5 min by absorbance measurements at Specord-250 spectrophotometer (Jena Analytic, Germany) by recording the absorption spectra in the range 200-600 $\mathrm{nm}$. Decrease of absorbance peak at $400 \mathrm{~nm}$ (attributed to the typical absorption of 4-NP) was used to evaluate the catalyst's activity. After the reaction, the $\mathrm{Au} / \mathrm{PET}$ membrane was thoroughly rinsed with deionized water and used in next 4 cycles without any additional pretreatment.

\section{Discussion}

The wide interest of researchers in the amazing properties of gold nanostructures significantly contributed to the development of new methods of their synthesis, the most often used being the electroless template-assisted assay based on application of the gold(I) trisodium disulphite electrolyte and formaldehyde as a reducing agent. Carrying out the deposition reaction at lower temperatures provides a low rate of gold(I) deposition however high quality of synthesized nanostructures.
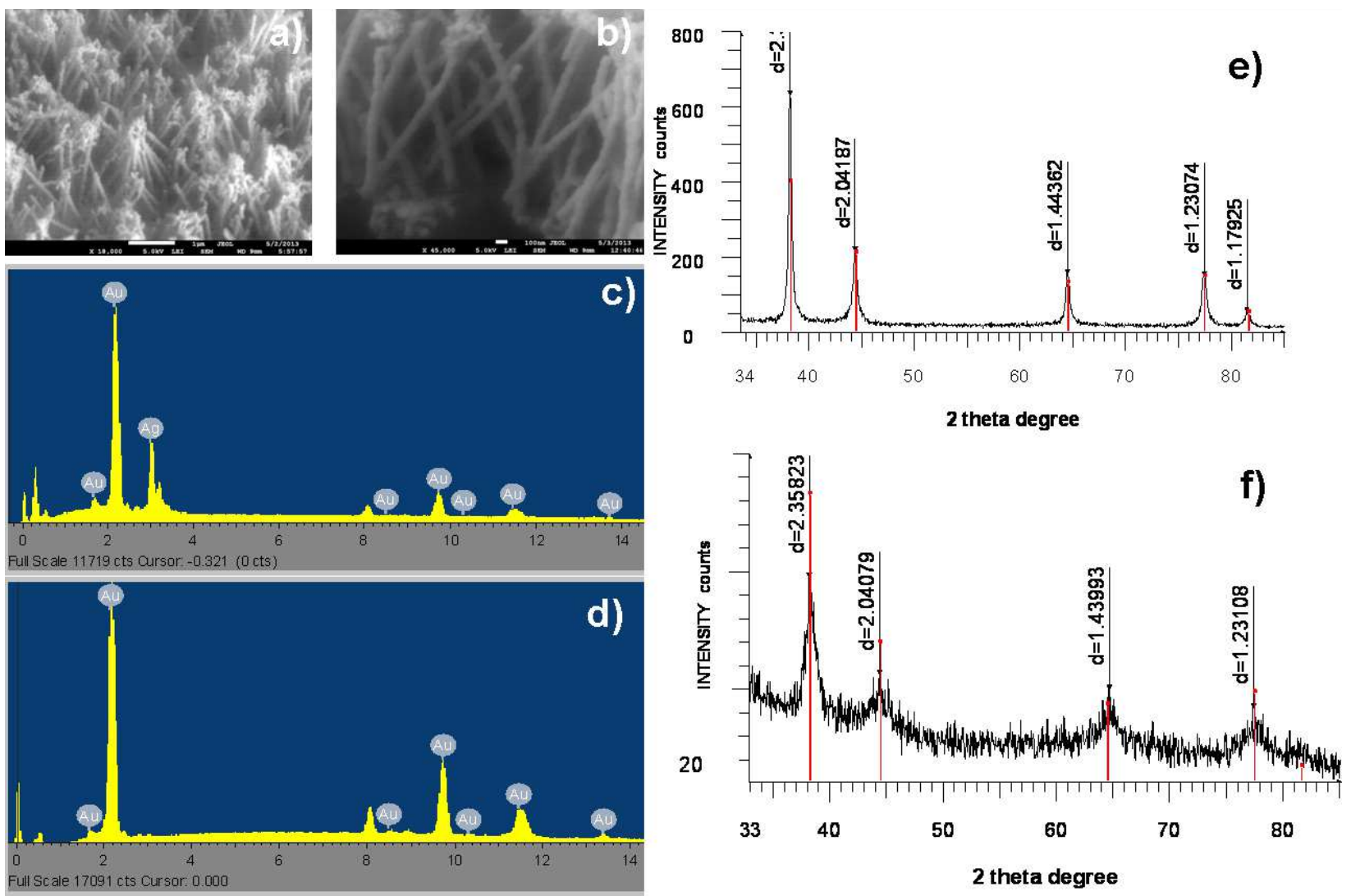

Fig. 1. SEM images of nanotubes arrays synthesized with $\mathrm{AS}_{\mathrm{I}}$ (a) and $\mathrm{AS}_{\mathrm{II}}$ (b). EDS spectra of GNT samples after $24 \mathrm{~h}$ deposition with $\mathrm{AS}_{\mathrm{I}}(\mathrm{c})$ and $\mathrm{AS}_{\mathrm{II}}(\mathrm{d})$ and corresponding XRD pattern (e), (f). 
Figure 1 shows SEM images of gold nanotube arrays produced after immersing of activated in $\mathrm{AS}_{\mathrm{I}}$ (1a) and $\mathrm{AS}_{\text {II }}$ (1b) PET membrane in plating solution for $24 \mathrm{~h}$ and after dissolving away the PET template. The metal tubes have monodispersed lengths uniform thickness reflecting the template membrane thickness. As it was calculated from Hagen-Poiseuille equation the wall thickness of the tubes for $\mathrm{AS}_{\mathrm{I}}$ was 20 and $43.8 \mathrm{~nm}$ for 1 and $5 \mathrm{~h}$ treated samples, respectively, after using $\mathrm{AS}_{\mathrm{II}}$ at the same deposition time the walls of gold nanotubes were finer: 6.05 and $8.4 \mathrm{~nm}$, respectively.

The chemical composition of gold assembling tubes was determined by EDX (Fig. 1c and d). The EDX spectrum for $\mathrm{AS}_{\mathrm{II}}$ with one main peak was observed, indicating that the nanotubes arrays were made up of metallic gold, a trace amount $(0.92 \%)$ of silver have been found on the outer walls of the nanotubes (the product of activation). Chemical composition of the $\mathrm{AS}_{\text {I }}$ includes up to $70 \%$ of silver on the outer walls, but inside of all tubes consist of pure gold. Thus, the $\mathrm{Au} / \mathrm{Ag} / \mathrm{PET}$ composites were prepared.

XRD analysis was used to characterize the chemical composition and crystal structure of nanotubes arrays (all measurements were carried out without PET template to avoid additional background that would come from polymer on XRD patterns). The typical XRD pattern and corresponding intensity of major peaks of $\mathrm{AS}_{\mathrm{I}}$ $(\mathrm{Au} / \mathrm{Ag})$ and $\mathrm{AS}_{\mathrm{II}}(\mathrm{Au})$ nanotubes are shown in Fig. 1e and $\mathrm{f}$. As a standard of gold the Powder Diffraction file N4-784 was used.

As it could be seen from XRD spectra the sample $\mathrm{AS}_{\text {I }}$ has a perfect crystalline structure rather than $\mathrm{AS}_{\text {II }}$ sample because the diffraction reflections are broadened in the latter. The diffraction pattern shown in Fig. 1e clearly shows peaks (111) (200) (220) and (311) characteristic for a face-centered cubic (fcc) lattice of gold [12]. Examination of Fig. 1e and f shows that the reflected intensity is much higher from (111) planes than that from (200) and (220) and Au nanotubes are predominately $\mathrm{Au}(111)$ oriented. It was unexpected that no diffraction pattern is detected for silver, although EDX analysis revealed that the content is up to $70 \%$. It could be explained by too small sizes of silver nanoparticles, also this "basic" layer of silver is used to strengthen the walls of the tubes.

All fcc parameters are listed in Table I. The average crystallite size was estimated from the diffracting planes along the direction normal to the $(h k l)$ plane applying the Scherrer formula (2).

The values of fcc for PDF N 4-784 are $a=4.0788 \pm$ $0.0003 \AA$ and $V=67.859 \pm 0.013 \AA^{3}$, respectively. These results suggest that the use of activated solution $\mathrm{AS}_{\mathrm{I}}$ based on double tetrahydrate sodium potassium salt of tartaric acid as a reducing agent allows obtaining a stronger coating with more perfect crystalline structure.

Catalytic reduction of $4-\mathrm{NP}$ to $4-\mathrm{AP}$ is the most acceptable model systems for investigation of metal nanoparticles/nanostructures as catalyst [13]. This re-
TABLE I

Gold nanotubes arrays $2 \theta$ peak positions, calculated crystal sizes and corresponding Au planes.

\begin{tabular}{c|c|c|c|c|c|c}
\hline \hline $\begin{array}{c}\text { Activation } \\
\text { solution }\end{array}$ & $2 \theta$ & $\beta$ & $\begin{array}{c}\text { Corresponding } \\
\text { plane }(h k l)\end{array}$ & $\begin{array}{c}\text { Crystal } \\
\text { size }[\mathrm{nm}]\end{array}$ & \multicolumn{2}{|c}{ Fcc parameters } \\
\hline \multirow{4}{*}{$\mathrm{AS}_{\text {I }}$} & 38.13 & 0.31 & $(111)$ & 5.72 & & \\
& 44.35 & 0.47 & $(200)$ & 4.16 & 4.0825 & 68.044 \\
& 64.68 & 0.44 & $(220)$ & 7.30 & \pm 0.0004 & \pm 0.022 \\
& 77.47 & 0.55 & $(311)$ & 11.62 & & \\
& 81.62 & 0.48 & $(222)$ & 2.92 & & \\
\hline \multirow{4}{*}{$\mathrm{AS}_{\text {II }}$} & 38.13 & 0.92 & $(111)$ & 1.92 & & \\
& 44.33 & 1.23 & $(200)$ & 1.58 & & \\
& 64.50 & 0.93 & $(220)$ & 3.47 & \pm .0797 & 67.90 \\
& 77.49 & 1.13 & $(311)$ & 5.63 & & \pm 0.116 \\
& 81.57 & 1.18 & $(222)$ & 1.19 & &
\end{tabular}

action does not proceed in the absence of catalyst nor requires elevated temperature and can be easily monitored by UV-vis spectrometry (4-NP is a strong visible absorber with a maximum absorbance at $400 \mathrm{~nm}$ ). Because the reaction is pseudo-first order in the presence of excess of reducing agent $\left(\mathrm{NaBH}_{4}\right)$ [14], this allows to study kinetics of the reaction by changing the amount of the starting reagent 4 -NP. The slope of a plot of the natural $\log$ of the absorbance at $400 \mathrm{~nm}$ yields $\left(A_{0} / A_{t}\right)$ the apparent rate constant $\left(\mathrm{min}^{-1}\right)$.

TABLE II

Kinetic data of reduction 4-NP to 4-AP, catalyzed by $\mathrm{Au} / \mathrm{Ag} / \mathrm{PET}$ and $\mathrm{Au} / \mathrm{PET}$ composites.

\begin{tabular}{c|c|c}
\hline \hline \multirow{2}{*}{$\begin{array}{c}\text { Deposition } \\
\text { time }[\mathrm{h}]\end{array}$} & \multicolumn{2}{|c}{ Constant rate $\left[\mathrm{min}^{-1}\right]$} \\
\cline { 2 - 3 } & $\mathrm{AS}_{\text {I }}(\mathrm{Au} / \mathrm{Ag} / \mathrm{PET})$ & $\mathrm{AS}_{\text {II }}(\mathrm{Au} / \mathrm{PET})$ \\
\hline 1 & $0.087 \pm 0.02$ & $0.041 \pm 0.01$ \\
5 & $0.084 \pm 0.01$ & $0.074 \pm 0.02$ \\
24 & $0.082 \pm 0.005$ & $0.05 \pm 0.01$
\end{tabular}

The reusability of prepared composites was checked consecutively for 5 times and as is shown in Table II in case of $\mathrm{AS}_{\text {I }}$ the rate constant slowly decreases for all samples. The 4-NP conversion degree (estimated from ratio $A_{0} / A_{t}$ for the first and the fifth cycle of $\mathrm{Au} / \mathrm{PET}$ testing) was found to change from $92.5 \%$ to $86.4 \%$ (1 h), $96.2 \%$ to $92.3 \%(5 \mathrm{~h})$ and $96.9 \%$ to $98.1 \%(24 \mathrm{~h})$. Surface of all membranes did not show any damages during intense stirring due to very strong adhesion of gold with the silver layer. This type Au/PET composites could be easily reused as a stable catalyst repeatedly.

In case of applying $\mathrm{AS}_{\mathrm{I}} \mathrm{Au} / \mathrm{PET}$ membrane catalysts, the rate constant is lower, and the effectiveness decreases after several cycles. The most active samples were obtained after $5 \mathrm{~h}$ deposition, thin nanotube walls consist of partially agglomerated gold particles supported on silver layer with size up to $10 \mathrm{~nm}$. After $24 \mathrm{~h}$ of deposition, the size of gold agglomerates is increased and as a result, the catalytic activity was reduced.

As it was mentioned above the reduction of 4-NP to 4-AP often used to evaluate noble nanoparticles as catalysts and gives possibility to compare results of other 
experiments on development of gold catalyst. Thus, 80 $100 \mathrm{~nm}$ gold nanotube arrays were synthesized in $30 \mu \mathrm{m}$ porous anodic aluminum oxide that gives catalytic rate constant $k=0.132 \mathrm{~min}^{-1}$ [11], $500 \mathrm{~nm}$ filigree gold nanotubes were obtained in polycarbonate template with adjusting of 4-(dimethylamino)pyridine in plating solution and shows $k=0.013 \mathrm{~s}^{-1}$ [13]. In our experiment the highest value of $k=0.087 \mathrm{~s}^{-1}$ was demonstrated after deposition within $1 \mathrm{~h}$ with activation solution $\mathrm{I}$.

The main advantages of applying $\mathrm{AS}_{\mathrm{I}}$ is the short deposition time (normally gold is deposited for $24 \mathrm{~h}$ ) and it is very important to reduce deposition time without strong impact on the structures and properties. The improving of prepared $\mathrm{Au} / \mathrm{PET}$ composite membranes could be achieved by increase of template thickness (up to $23-30 \mu \mathrm{m})$ as well as the pore diameter.

\section{Conclusions}

The fabrication of composites with embedded gold nanotubes inside the pores of PET track-etched membranes as well as improving deposition techniques are demonstrated. Applying of the potassium sodium tartrate as reducing agent at the stage of activation of template allows us to prepare more effective $\mathrm{Au} / \mathrm{Ag} / \mathrm{PET}$ membrane catalyst, then the same samples activated with "classical" ammonia silver nitrate solution.

\section{Acknowledgments}

This publication has been made within the Sub-project "Creating of filtration material and metal nanostructures based on track membranes" which is funded under the Technology Commercialization Project, supported by the World Bank and the Government of the Republic of Kazakhstan. The authors would like to thank Dr. Sergey Kislitsyn (INP) for his help with XRD characterisation.

\section{References}

[1] S.K. Chakarvarti, Indian J. Phys. 83, 737 (2009).

[2] R. Spohr, C. Zet, B.E. Fischer, H. Kiesewetter, P. Apel, I. Gunko, T. Ohgai, L. Westerberg, Nucl. Instrum. Methods Phys. Res. B 268, 676 (2010).

[3] P.Yu. Apel, S.N. Dmitriev, Adv. Nat. Sci., Nanosci. Nanotechnol. 2, 013002 (2011).

[4] L.A. Baker, P. Jin, Ch.R. Martin, Crit. Rev. Solid State Mater. Sci. 30, 183 (2005).

[5] P. Shao, G. Ji, P. Chen, J. Memb. Sci. 255, 1 (2005).

[6] Z. Siwy, L. Trofin, P. Kohli, L.A. Baker, C. Trautmann, C.R. Martin, J. Am. Chem. Soc. 127, 5000 (2005).

[7] L.T. Sexton, L.P. Horne, Ch.R. Martin, Mol. BioSyst. 3, 667 (2007).

[8] M. Yang, F. Qu, Biosens. Bioelectron. 23, 414 (2007).

[9] Sh. Guo, D. Wen, Talanta 77, 1510 (2009).

[10] Ya.B. Mollamahalle, M. Ghorbani, A. Dolati, Electrochim. Acta 75, 157 (2012).

[11] Y. Yu, K. Kant, J.G. Shapter, Microporous Mesoporous Mater. 153, 131 (2012).

[12] J.A. Abys, J.J. Maisano, U.S. Patent 6,126,807 (2000).

[13] F. Muench, U. Kunz, C. Neetzel, S. Lauterbach, H.J. Kleebe, W. Ensinger, Langmuir 27, 430 (2011).

[14] Z.D. Pozun, S.E. Rodenbusch, E. Keller, K. Tran, W. Tang, K.J. Stevenson, G. Henkelman, J. Phys. Chem. 117, 7598 (2013). 